\title{
Comunicação
}

\section{Produção e caracterização da bananeira 'Prata Anã' (AAB) em dois ciclos de produção (Juazeiro, Bahia) ${ }^{1}$}

\author{
Marlon Jocimar Rodrigues da Silva², João Marcos Chagas dos Anjos ${ }^{2}$, Paulo Ricardo Rodrigues de Jesus ${ }^{2}$, \\ Gabiane Souza dos Santos ${ }^{2}$, Flávio Bastos Ferreira Lima ${ }^{3}$, Valtemir Gonçalves Ribeiro ${ }^{4}$
}

\begin{abstract}
RESUMO
A avaliação do comportamento de genótipos de bananeira em diferentes ecossistemas é essencial ao programa de melhoramento genético, tornando-se de fundamental importância para o sistema produtivo. O objetivo deste trabalho foi avaliar o crescimento da bananeira 'Prata Anã' (AAB), nos $1^{\circ}$ e $2^{\circ}$ ciclos de produção, e os atributos físico-químicos dos frutos, no Submédio São Francisco. As mudas foram produzidas pelo processo de cultura de tecidos, na Biofábrica de Cruz das Almas, BA, e transplantadas para o campo com seis meses de idade, cultivadas no espaçamento $3 \times 3 \mathrm{~m}$. Foram avaliados os ciclos de produção (em dias) e, em cada ciclo, a altura das plantas, o perímetro do pseudocaule e o número de folhas adultas. Quanto à produção, foram avaliadas as seguintes características: massa da matéria fresca do cacho; número de pencas e de frutos por cacho; massa da matéria fresca da $2^{\mathrm{a}}$ penca; número, comprimento e diâmetro de frutos da $2^{a}$ penca; relação polpa/casca; firmeza; $\mathrm{pH}$; sólidos solúveis (SS); acidez titulável (AT) e a relação SS/AT. Verificou-se diferença significativa para a maioria das variáveis analisadas: o segundo ciclo de produção da bananeira 'Prata Anã' foi menor do que o primeiro, sendo que, no segundo ciclo, ocorreram tendências de maior crescimento e de melhor desempenho dos caracteres que expressam a produção e a qualidade física dos frutos.
\end{abstract}

Palavras-chave: Musa sp., desempenho agronômico, características físico-químicas.

\section{ABSTRACT}

\section{Production and characterization of banana 'Prata Anã' (AAB) in two production cycles (Juazeiro, Bahia/Brazil)}

Evaluation of the behavior of banana genotypes in different ecosystems is essential in a breeding program, making it crucial for the production system. The aim of this study was to evaluate the growth behavior of banana 'Prata Anã' $(\mathrm{AAB})$ in the $1^{\text {st }}$ and $2^{\text {nd }}$ cycles of production and fruit physical-chemical attributes in the sub- middle region of the São Francisco River Valley. The seedlings were produced by tissue culture in a Biofactory in Cruz das Almas - BA and transplanted to the field after six months, in a spacing of $3 \times 3 \mathrm{~m}$. It was evaluated the production cycles (in days) and in each cycle, plant height, pseudostem perimeter and the number of mature leaves. The following characteristicsof production were evaluated: bunch fresh mass, number of cluster and fruits per bunch; fresh mass of the $2^{\text {nd }}$ cluster, number, length and diameter of fruits in the $2^{\text {nd }}$ cluster; pulp/skin ratio; firmness, $\mathrm{pH}$, soluble solids (SS), titratable acidity (TA) and SS/TA ratio. There was significant difference for most variables: the second production cycle of banana 'Prata Anã' was shorter than the first, on the second cycle occurred trends of increased growth and better performance of the characters that express production and fruit physical quality.

Key words: Musa sp., agronomic performance, physical-chemical characteristic.

Recebido para publicação em 29/06/2012 e aprovado em 22/11/2012.

Apoio financeiro: Fundação de Amparo à Pesquisa do Estado da Bahia.

2 Graduandos em Engenharia Agronômica. Universidade do Estado da Bahia, Avenida Edgard Chastinet Guimarães, São Geraldo, 48905-680, Juazeiro, Bahia, Brasil. marlonjocimar@gmail.com (Bolsista FAPESB / autor para correspondência); jmanjos@gmail.com; paulinho.rrj@hotmail.com; gabbysouza_20@hotmail.com

${ }^{3}$ Engenheiro-Agrônomo. Departamento de Tecnologia e Ciências Sociais, Universidade do Estado da Bahia, Avenida Edgard Chastinet Guimarães, São Geraldo, 48905-680, Juazeiro, Bahia, Brasil. fbastoslima@gmail.com

${ }^{4}$ Engenheiro-Agrônomo, Doutor. Departamento de Tecnologia e Ciências Sociais, Universidade do Estado da Bahia, Avenida Edgard Chastinet Guimarães, São Geraldo, 48905680, Juazeiro, Bahia, Brasil. vribeiro@uneb.com 


\section{INTRODUÇÃO}

A produção brasileira de bananas está distribuída por todo o território nacional, sendo a região nordeste a maior produtora $(39,1 \%)$, seguida das regiões sudeste $(31,7 \%)$, sul $(13,5 \%)$, norte $(11,8 \%)$ e centro-oeste $(3,5 \%)$, em uma área estimada de 514.366 ha (IBGE, 2012).

Na Região do Semiárido brasileiro, destacam-se os polos de produção de Minas Gerais, em Janaúba e Jaíba; da Bahia, em Juazeiro, Bom Jesus da Lapa, Barreiras, Livramento de Nossa Senhora, Caraíbas, Guanambi, Urandi e Sebastião Laranjeiras; do Pernambuco, em Petrolina e Santa Maria da Boa Vista; no Rio Grande do Norte, no Vale do Açu; do Sergipe, em Platô de Neópolis, e do Ceará, em Chapada do Apodi e Baixo Acaraú (Donato et al., 2009).

A prevalência do cultivo de bananeiras tipo Prata, no País, com destaque para a 'Prata-Anã' e a 'Pacovan', evidencia a tradição de seu cultivo e a sua boa aceitação comercial (Donato et al., 2009). A bananeira 'Prata-Anã', também conhecida por 'Enxerto', é uma planta vigorosa, que apresenta porte de médio a baixo (2,0 a 3,5 $\mathrm{m}$ de altura), sendo seus frutos típicos do subgrupo Prata (Silva et al., 1999).

A preferência por frutos dessa variedade pode ser explicada, em parte, por apresentar o sabor típico de 'Prata', ao qual o consumidor já está habituado, sendo alta a frequência de seu consumo, especialmente no nordeste do Brasil e, também, por seu gosto mais adocicado (Matsuura et al. 2004; Damatto Junior et al., 2005).

A avaliação do comportamento de genótipos de bananeiras em diferentes ecossistemas é essencial ao programa de melhoramento genético, servindo, ainda, para indicar cultivares promissores ao sistema produtivo local. Por essas razões, o objetivo deste trabalho foi avaliar o crescimento da bananeira 'Prata Anã', no $1^{\circ}$ e $2^{\circ}$ ciclo de produção, e os atributos físico-químicos dos frutos, no Submédio São Francisco, Juazeiro, BA.

\section{MATERIAL E MÉTODOS}

O experimento foi realizado na área experimental da Universidade do Estado da Bahia, Departamento de Tecnologia e Ciências Sociais (UNEB/DTCS), situada no município de Juazeiro, BA (latitude: 9²5’43" S; longitude: 40³2'14" W; altitude: $384 \mathrm{~m}$ ), durante os meses de abril de 2010 a dezembro de 2011. O clima da região é segundo Köepen, do tipo Bswh, correspondente a muito quente, semiárido e com estação chuvosa limitada. Durante a condução do experimento, os dados meteorológicos foram obtidos pela Estação de Meteorologia da UNEB/DTCS. Os valores médios de temperaturas e umidades relativas máximas, médias e mínimas foram de 32,1, 26 e $21,1^{\circ} \mathrm{C} ; 97,1,74,1$ e $45,3 \%$, respectivamente; a preci- pitação pluviométrica foi de $1,2 \mathrm{~mm}$ e a velocidade do vento (medida a $2 \mathrm{~m}$ de altura em relação à superfície do solo), de 166,9 $\mathrm{km} \mathrm{dia}^{-1}$.

O solo da unidade experimental, segundo análise do Laboratório de Análise de Solo, Água e Calcário (LASAC), da UNEB/DTCS, em amostra da camada de 0 a $20 \mathrm{~cm}$, é da classe textural Franca (média), com $42,5 \mathrm{~g} \mathrm{~kg}^{-1}$ de areia, $44,2 \mathrm{~g} \mathrm{~kg}^{-1}$ de silte e $13,3 \mathrm{~g} \mathrm{~kg}^{-1}$ de argila, apresentando ainda os seguintes atributos químicos: $\mathrm{pH}\left(\mathrm{H}_{2} \mathrm{O}\right)=5,38$; condutividade elétrica $=0,47 \mathrm{dS} \mathrm{m}{ }^{-1} ; \mathrm{Ca}^{+2}=3,99 \mathrm{cmol}_{\mathrm{c}} \mathrm{kg}^{-1}$; $\mathrm{Mg}^{+2}=3,31 \mathrm{cmol}_{\mathrm{c}} \mathrm{kg}^{-1} ; \mathrm{K}^{+}=0,26 \mathrm{cmol}_{\mathrm{c}} \mathrm{kg}^{-1} ; \mathrm{Na}^{+}=0,10$ $\mathrm{cmol}_{\mathrm{c}} \mathrm{kg}^{-1} ; \mathrm{H}^{+}+\mathrm{Al}^{+3}=0,99 \mathrm{cmol}_{\mathrm{c}} \mathrm{kg}^{-1} ; \mathrm{T}=8,65 \mathrm{cmol}_{\mathrm{c}} \mathrm{kg}^{-1} \mathrm{e}$ $\mathrm{V}=88,55 \%$.

Mudas de bananeira 'Prata Anã', pertencentes ao grupo $\mathrm{AAB}$, produzidas, por cultura de tecidos, na Biofábrica de Cruz das Almas, BA, foram transplantadas para o campo, aos seis meses de idade, em espaçamento $3 \mathrm{~m} \mathrm{x} 3 \mathrm{~m}$. Durante os ciclos de produção, foram adotadas as seguintes práticas culturais: irrigação, controle de plantas daninhas, eliminação da inflorescência masculina e corte do pseudocaule após a colheita. O sistema de irrigação foi o localizado, por microaspersão, utilizando-se aspersores com vazão de $38 \mathrm{~L} / \mathrm{h}$. O manejo foi feito com base na evaporação obtida no Tanque Classe "A". Nos dois primeiros ciclos de produção, as características de crescimento avaliadas foram: altura de planta $(\mathrm{m})$, medida do nível do solo até a roseta foliar; perímetro do pseudocaule $(\mathrm{cm})$, medido a $30 \mathrm{~cm}$ do solo, com fita métrica graduada; e número de folhas vivas.

Em relação aos ciclos da cultura, foram avaliados o número de dias entre o plantio e a primeira colheita (primeiro ciclo de produção), e o número de dias entre a colheita da planta-mãe e a da planta-filha (segundo ciclo de produção), sendo que o plantio ocorreu em 05 de abril/ 2010; a primeira colheita, entre 12 de março a 29 de abril/ 2011, data, esta, a do primeiro corte, iniciando-se, portanto, o segundo ciclo; e, entre 28 de outubro e 22 de dezembro/2011, procedeu-se à colheita do segundo ciclo da cultura.

Após a colheita, foram mensuradas as seguintes características de produção: massa da matéria fresca do cacho $(\mathrm{kg})$, medida por meio de balança pendular, tipo relógio; número de pencas e de frutos por cacho; massa da matéria fresca da $2^{\mathrm{a}}$ penca $(\mathrm{kg})$; número de frutos da $2^{\mathrm{a}}$ penca; comprimento de frutos da $2^{\mathrm{a}}$ penca $(\mathrm{cm})$, medido, entre as duas extremidades, com régua graduada; e diâmetro de frutos da $2^{a}$ penca $(\mathrm{mm})$, medido na região central dos frutos. Foram realizadas ainda as seguintes análises de qualidade dos frutos: relação polpa/casca; firmeza (N); pH; sólidos solúveis ( $\mathrm{SS}$, em ${ }^{\circ} \mathrm{Brix}$ ), determinado por refratometria; acidez titulável (AT, expressa em g.ácido málico/100 ml polpa) (Instituto Adolfo Lutz, 2008), e a relação SS/AT (ratio). 
Os cachos foram colhidos quando a primeira penca atingiu a Classe 2 de maturação (verde com traços amarelos) de acordo com a escala de notas proposta por Von Loesecke (PBMH: PIF, 2006). Para as análises de qualidade dos frutos, foram utilizadas as segundas pencas de cinco cachos das bananeiras 'Prata Anã'. Após colhidos, os frutos foram encaminhados para o LASAC da UNEB/ DTCS, sem serem climatizados, e permaneceram em condições ambientais até o amadurecimento, momento em que foram realizadas as análises físico-químicas.

Para as características de crescimento e produção, foi adotado o delineamento experimental inteiramente casualizado, com dois tratamentos (ciclos), dez repetições e duas plantas úteis por unidade experimental. Para as análises laboratoriais (físico-químicas), utilizou-se o mesmo delineamento, porém, com cinco repetições e cinco frutos por repetição. Os dados foram submetidos à análise de variância (teste F), sendo as médias comparadas entre si pelo teste Tukey, a 5\% de probabilidade.

\section{RESULTADOS E DISCUSSÃO}

Nas condições edafoclimáticas de Juazeiro, BA, a bananeira 'Prata Anã' apresentou primeiro ciclo de produção (do plantio à primeira colheita) de 347,2 dias, ao passo que para o segundo ciclo de produção (entre a colheita da planta-mãe e a da planta-filha) foram necessários 224,6 dias (Tabela 1). Valores semelhantes para o mesmo cultivar foram encontrados por Donato et al. (2006), nas condições de Guanambi, BA, local, com temperaturas médias semelhantes às encontradas durante a realização deste trabalho, ao passo que Oliveira et al. (2007), em Visconde do Rio Branco, e Gonçalves et al. (2008), em Janaúba, ambos em Minas Gerais, verificaram valores superiores, ao avaliar o primeiro ciclo de produção do mesmo cultivar (467 e 424 dias, respectivamente). No entanto, valores próximos foram verificados no segundo ciclo de produção (238 e 190 dias, respectivamente) por esses autores.

Na Tabela 1, encontram-se, ainda, os valores referentes às características de crescimento (altura de planta, perímetro do pseudocaule e número de folhas vivas por planta), produção e qualidade física de frutos da bananeira 'Prata Anã', no primeiro e segundo ciclo de produção.

Em relação à altura da planta e à circunferência do pseudocaule, houve um aumento estatisticamente significativo nos valores do primeiro para o segundo ciclo, da ordem de 1,0 m e 17,22 cm, respectivamente, o que está condizente com a literatura especializada (Souza et al., 2011). Essas variáveis são consideradas dois dos principais descritores, sob o ponto de vista fitotécnico e de melhoramento, pois estão ligadas aos aspectos de densidade de plantio, produção e manejo da cultura (Gonçalves et al., 2008). Donato et al. (2006) também observaram incremento nos valores destas variáveis, do primeiro para o segundo ciclo de produção, quando estudaram 13 genótipos de bananeiras, dentre eles a 'Prata Anã'.

O número de folhas na colheita, no primeiro ciclo de produção, foi de 8,95 , ao passo que, no segundo ciclo, houve um aumento para 10,35 folhas, ou seja, um incremento médio de 1,4 folhas. Isso contribuiu, certamente, para que as massas das pencas e dos cachos aumentassem do primeiro para o segundo ciclo $(1,47 \mathrm{~kg}$ para 2,53 $\mathrm{kg} ; 13,93 \mathrm{~kg}$ para $22,56 \mathrm{~kg}$, respectivamente). O enchimento dos frutos está diretamente relacionado com o número de folhas vivas na colheita (Lima et al., 2005).

Segundo Silva et al. (2002), o primeiro ciclo de produção da bananeira não é o momento oportuno para se analisar a massa da matéria fresca do cacho, na maioria dos genótipos, uma vez que o caráter pode aumentar do primeiro para o segundo ciclo da cultura, o que foi corroborado neste trabalho. Todavia, os valores encontrados, tanto no primeiro quanto no segundo ciclo, neste trabalho, foram superiores aos encontrados por Oliveira et al. (2008), em Rio Branco, AC, e por Gonçalves et al. (2008), em Janaúba, MG.

O número de pencas por cacho não diferiu estatisticamente entre o primeiro $(9,15$ pencas) e o segundo ciclo de produção (9,20 pencas). Oliveira et al. (2008) destacam a importância dessa variável, como sendo de interesse para o produtor e fundamental para o melhoramento genético da bananeira, uma vez que a penca constitui-se na unidade comercial.

Embora o número de pencas não tenha diferido entre os ciclos avaliados, observou-se um aumento considerável no número de frutos por cacho, passando de 124,3 frutos, no primeiro ciclo, para 140,2 frutos, no segundo. Isso demonstra que, de modo geral, o número de frutos por penca foi maior no segundo ciclo de produção. Silva et al. (2002) afirmam que o primeiro ciclo também não deve ser considerado conclusivo para análise do desempenho de genótipos quanto ao número de frutos, pois há uma tendência de elevação nos valores desse caráter em ciclos posteriores, semelhantemente ao verificado neste trabalho.

Como relatado anteriormente, observou-se um incremento nos valores de massa da matéria fresca da segunda penca, em torno de $72 \%$, ao passar de $1,47 \mathrm{~kg}$, no primeiro ciclo, para 2,53 kg, no segundo. Resultados semelhantes foram encontrados por Souza et al. (2011), para a 'FigoCinza', observando-se incrementos desta variável, todavia, sem haver aumento significativo no número de frutos.

Para todos os caracteres relacionados com as características físicas dos frutos, observou-se incremento do primeiro para o segundo ciclo de produção. Em relação ao comprimento de frutos, segundo a Associação Central dos Fruticultores do norte de Minas - ABANORTE, frutos 
do subgrupo Prata são classificados em três categorias, quanto ao comprimento: Exportação (maior que $16 \mathrm{~cm}$ ), Primeira (maior que $14 \mathrm{~cm}$ ) e Segunda (maior que $12 \mathrm{~cm}$ ) (FRUTISÉRIES, 2000). Os resultados obtidos com os frutos da 'Prata-Anã', no primeiro ciclo, foram ligeiramente inferiores ao mínimo necessário para classificá-los como frutos de Primeira, mas suficientes para enquadrá-los como de Segunda. No entanto, os frutos obtidos no segundo ciclo de produção apresentaram comprimentos que permitiram a classificação como tipo Exportação.

O diâmetro de frutos é, normalmente, utilizado para indicar o ponto de colheita. O incremento no valor desse caráter foi de 4,61 cm (o que corresponde a um aumento de $14,22 \%$ ), passando de $32,42 \mathrm{~cm}$, no primeiro ciclo, para $37,03 \mathrm{~cm}$, no segundo. Em média, os diâmetros de frutos encontrados neste trabalho foram semelhantes aos encontrados por Donato et al. (2006), que trabalharam com a 'Prata Anã', no município de Guanambi, região sudoeste da Bahia.

Os valores da relação polpa/casca aumentaram de 2,19 (primeiro ciclo), para 2,7 (segundo ciclo). De modo geral, esses valores foram superiores aos encontrados por Cerqueira et al. (2002), os quais trabalharam com diferentes híbridos e cultivares de bananeiras. Damatto Junior $e t$ al. (2005) também avaliaram a relação polpa/casca dos cultivares Prata Anã e Prata Zulu, encontrando valores de 1,81 e 3,43, respectivamente.

Os frutos obtidos no segundo ciclo de produção apresentaram maior firmeza (14,2 N), quando comparados com os valores de firmeza dos frutos do primeiro ciclo $(11,3 \mathrm{~N})$. A diferença nos valores de firmeza pode ser explicada com base no índice de maturação do fruto. É sabido que bananas são geralmente colhidas quando a casca apresenta coloração ainda verde, mas já em estádio de maturação fisiológica. Uma pequena variação desse estádio pode, entretanto, alterar a firmeza dos frutos (Souza et al., 2011). A redução na firmeza da polpa da banana ocorre, geralmente, por ação de enzimas que atuam na parede celular. $\mathrm{O}$ amaciamento dos frutos está associado à hidrólise de amido e à solubilização das substâncias pécticas e, também, à perda de água; alterações que ocorrem durante o amadurecimento, e que, a exemplo da solubilização das substâncias pécticas, são bem definidas na banana, por se tratar de fruto climatérico (Silva et al., 2006a; Silva et al., 2006b).

Os teores de sólidos solúveis (SS), acidez titulável (AT), a relação SS/AT e o pH (Tabela 2) são os atributos que melhor definem a qualidade do fruto da bananeira (Chitarra \& Chitarra, 2005). O pH encontrado nos frutos do segundo ciclo de produção mostrou-se inferior $(4,55)$ ao dos frutos do primeiro ciclo $(5,17)$. Esses resultados diferem dos encontrados por Souza et al. (2011), em Botucatu, SP, ao não se verificarem diferenças significativas, quando se avaliaram frutos da 'Figo-Cinza', nos dois primeiros ciclos de produção. Por outro lado, os valores médios de $\mathrm{pH}$ aqui encontrados foram semelhantes aos descritos por Gomes et al. (2007), para a 'Prata Anã', no norte e noroeste do Rio de Janeiro.

O teor de sólidos solúveis (SS) não diferiu estatisticamente nos dois ciclos avaliados, sendo inferiores aos encontrados por Gomes et al. (2007), que obtiveram, para 'Prata Anã', valores de 25,6 ${ }^{\circ} \mathrm{Brix}$. No entanto, observouse um aumento nos valores de acidez titulável, passando de 0,47 g.ácido málico/100 ml polpa, no primeiro ciclo de produção, para 0,67 g.ácido málico/100 ml polpa, no segundo ciclo.

Tabela 1. Valores médios dos ciclos de produção (CP), altura de plantas na colheita (ALPC), perímetro do pseudocaule na colheita (PPCC), número de folhas vivas por planta (NFVP), massa da matéria fresca do cacho (MMFC), número de pencas por cacho (NPCA), número de frutos por cacho (NFCA), massa da matéria fresca da $2^{\mathrm{a}}$ penca (MMFSP), número de frutos da $2^{\mathrm{a}}$ penca (NFSP), comprimento de frutos (CF), diâmetro de frutos (DF), relação polpa casca (RPC) e firmeza (FIR) de frutos da bananeira 'Prata Anã' no $1^{\circ}$ e $2^{\circ}$ ciclo de produção, no Submédio São Francisco. Juazeiro-BA, 2010-2011

\begin{tabular}{|c|c|c|c|c|c|}
\hline 'Prata Anã' & CP (dias) & ALPC (m) & & $\operatorname{PPCC}(\mathrm{cm})$ & NFVP \\
\hline $1^{\circ}$ Ciclo & $347,2 \mathrm{a}$ & $2,27 \mathrm{~b}$ & & $67,08 \mathrm{~b}$ & $8,95 \mathrm{~b}$ \\
\hline $2^{\circ}$ Ciclo & $224,6 \mathrm{~b}$ & $3,27 \mathrm{a}$ & & $84,30 \mathrm{a}$ & $10,35 \mathrm{a}$ \\
\hline \multirow[t]{2}{*}{$\mathrm{CV}(\%)$} & 2,14 & 9,11 & & 8,35 & 12,03 \\
\hline & MMFC (kg) & NPCA & & NFCA & MMFSP (kg) \\
\hline $1^{\circ}$ Ciclo & $13,93 \mathrm{~b}$ & $9,15 \mathrm{a}$ & & $124,3 \mathrm{~b}$ & $1,47 \mathrm{~b}$ \\
\hline $2^{\circ}$ Ciclo & $22,56 \mathrm{a}$ & $9,20 \mathrm{a}$ & & $140,2 \mathrm{a}$ & $2,53 \mathrm{a}$ \\
\hline \multirow[t]{2}{*}{$\mathrm{CV}(\%)$} & 20,36 & 8,37 & & 11,71 & 18,62 \\
\hline & NFSP & $\mathrm{CF}(\mathrm{cm})$ & DF (mm) & RPC & $\operatorname{FIR}(\mathbf{N})$ \\
\hline $1^{\circ}$ Ciclo & $15,15 \mathrm{a}$ & $13,96 \mathrm{~b}$ & $32,42 \mathrm{~b}$ & $2,19 \mathrm{~b}$ & $11,3 \mathrm{~b}$ \\
\hline $2^{\circ}$ Ciclo & $15,90 \mathrm{a}$ & $16,24 \mathrm{a}$ & $37,03 \mathrm{a}$ & $2,70 \mathrm{a}$ & $14,2 \mathrm{a}$ \\
\hline $\mathrm{CV}(\%)$ & 7,88 & 10,41 & 5,29 & 17,2 & 10,17 \\
\hline
\end{tabular}

Médias seguidas por letras distintas nas colunas diferem entre si pelo teste Tukey, a 5\% de probabilidade. 
Tabela 2. Valores médios de pH, acidez titulável (AT), sólidos solúveis (SS) e relação SS/AT (RATIO) de frutos da bananeira 'Prata Anã' no $1^{\circ}$ e $2^{\circ}$ ciclo de produção, no Submédio São Francisco. Juazeiro-BA, 2010-2011

\begin{tabular}{lcccc}
\hline 'Prata Anã' & $\mathbf{p H}$ & AT $(\mathbf{g} / \mathbf{1 0 0} \mathbf{~ m l})$ & SS $\left({ }^{\circ} \mathbf{B r i x}\right)$ & RATIO \\
\hline $1^{\circ}$ Ciclo & $5,17 \mathrm{a}$ & $0,47 \mathrm{~b}$ & $23,06 \mathrm{a}$ & $49,06 \mathrm{a}$ \\
$2^{\circ}$ Ciclo & $4,55 \mathrm{~b}$ & $0,67 \mathrm{a}$ & $22,47 \mathrm{a}$ & $33,54 \mathrm{~b}$ \\
\hline $\mathrm{CV}(\%)$ & 1,75 & 15,35 & 5,06 & 15,52 \\
\hline
\end{tabular}

Médias seguidas por letras distintas nas colunas diferem entre si pelo teste Tukey, a 5\% de probabilidade.

Cerqueira et al. (2002) avaliaram 16 híbridos e quatro cultivares, dentre os quais a 'Prata Comum' e o híbrido da 'Prata Anã' (SH 3640), sendo verificados, para a acidez titulável, valores de 0,52 e 0,48\% de ácido málico e, para a relação SS/AT, valores de 44,72 e 40,22, respectivamente, índices próximos, portanto, aos encontrados no primeiro ciclo $(49,42)$, porém, acima daqueles do segundo $(34,40)$, sendo que os valores de AT encontrados no segundo ciclo, neste trabalho, foram superiores aos encontrados por Matsuura et al. (2002), para a 'Pacovan' (0,64\% de ácido málico), a qual, normalmente, apresenta frutos mais ácidos.

\section{CONCLUSÃO}

O período de colheita da bananeira 'Prata Anã' foi menor, durante o seu segundo ciclo de produção, no qual ocorreram tendências de maior crescimento e desempenhos dos caracteres que expressam a produção, tendo sido ele igualmente superior ao primeiro, para promover melhores características físicas de frutos.

\section{REFERÊNCIAS}

Cerqueira RC, Silva SO \& Medina VM (2002) Características póscolheita de frutos de genótipos de bananeira (Musa spp.). Revista Brasileira de Fruticultura, 24:654-657.

Chitarra MIF \& Chitarra AB (2005) Pós-colheita de Frutos e Hortaliças: fisiologia e manuseio. $2^{\mathrm{a}}$ ed. Lavras, Universidade Federal de Lavras. 785p.

Damatto Júnior ER, Campos AJ, Manoel L, Moreira GC, Leonel S \& Evangelista RM (2005) Produção e caracterização de frutos de bananeira 'Prata-Anã' e 'Prata-Zulu'. Revista Brasileira de Fruticultura, 27:440-443.

Donato SLR, Silva SO, Lucca Filho AO, Lima MB, Domingues H \& Alves JS (2006) Comportamento de variedades e híbridos de bananeira (Musa spp.), em dois ciclos de produção no sudoeste da Bahia. Revista Brasileira de Fruticultura, 28:139-144.

Donato SRL, Arantes AM, Silva SO \& Cordeiro ZJM (2009) Comportamento fitotécnico da bananeira 'Prata Anã' e de seus híbridos. Pesquisa Agropecuária Brasileira, 44:1608-1615.

FRUTISÉRIES (2000) Banana: Minas Gerais. Brasília, Ministério da Integração Nacional. 8p. (Boletim técnico, 6).

Gomes MC, Viana AP, Oliveira JG, Pereira MG, Gonçalves GM \& Ferreira CF (2007) Avaliação de germoplasma elite de bananeira. Revista Ceres, 54:185-190

Gonçalves VD, Niestsche S, Pereira MCT, Silva SO, Santos TM, Oliveira JR, Franco LRL \& Ruggiero C (2008) Avaliação dos cultivares de bananeira Prata-anã, Thap Maeo e Caipira em diferentes sistemas de plantio no norte de Minas Gerais. Revista Brasileira de Fruticultura, 30:371-376.
Instituto Brasileiro de Geografia e Estatística - IBGE (2012) Levantamento sistemático da produção agrícola. Disponível em: <http://www.ibge.gov.br/home/estatistica/indicadores/ agropecuaria/lspa/lspa_201208.pdf >. Acessado em: 21 de outubro de 2012

Instituto Adolfo Lutz (2008) Conservas vegetais, frutas e produtos de frutas. In: Métodos físico-químicos para análises de alimentos. $4^{\mathrm{a}}$ ed. São Paulo, Instituto Adolfo Lutz. p.571-591.

Lima MB, Silva SO, Jesus ON, Oliveira WSJ, Guarrido MS \& Azevedo RL (2005) Avaliação de cultivares e híbridos de bananeira no Recôncavo baiano. Ciência e Agrotecnologia, 29:515-520.

Matsuura FCAU, Cardoso RL \& Ribeiro DE (2002) Qualidade sensorial de frutos de híbridos de bananeira cultivar Pacovan. Revista Brasileira de Fruticultura, 24:263-266.

Matsuura FCAU, Costa JIP \& Folegatti MIS (2004) Marketing de banana: preferências do consumidor quanto aos atributos de qualidade dos frutos. Revista Brasileira de Fruticultura, 26:4852

Oliveira CAP, Peixoto CP, Silva SO, Ledo CAS \& Salomão LCC (2007) Genótipos de bananeira em três ciclos na Zona da Mata Mineira. Pesquisa Agropecuária Brasileira, 42:173-181.

Oliveira TK, Lessa LS, Silva SO \& Oliveira JP (2008) Características agronômicas de genótipos de bananeira em três ciclos de produção em Rio Branco-AC. Pesquisa Agropecuária Brasileira, 43:1003-1010.

PBMH: PIF (2006) Programa Brasileiro para a Moder-nização da Horticultura: Produção Integrada de Frutas. Normas de classificação de banana. São Paulo, CEAGESP. 2p.

Silva CS, Lima LC, Santos HS, Camili EC, Vieira CRYI, Martin CS \& Vieites RL (2006a) Amadurecimento da banana-prata climatizada em diferentes dias após a colheita. Ciência e Agrotecnologia, 30:103-111.

Silva EA, Boliani AC \& Corrêa LS (2006b) Avaliação de cultivares de bananeira (Musa sp.) na região de Selvíria-MS. Revista Brasileira de Fru-ticultura, 28:101-103.

Silva SO, Alves EJ, Shepherd K \& Dantas JLL (1999) Cultivares. In: Alves EJA (Ed.) Cultura da banana: aspectos técnicos, socioeconômicos e agroindustriais. Brasília, Embrapa-SPI/Cruz das Almas, Embrapa-CNPMF. p.85-106.

Silva SO, Flores JC \& Lima Neto FP (2002) Avaliação de cultivares e híbridos de bananeira em quatro ciclos de produção. Pesquisa Agropecuária Brasileira, 37:1567-1574.

Souza ME, Leonel S \& Martin RL (2011) Caracterização do cultivar de bananeira 'Figo-Cinza' em dois ciclos de produção. Revista Brasileira de Fruticultura, VE:461-465. 